\title{
Distributed Model Predictive Control for Active Power Control of Wind Farm
}

\author{
Zhao, Haoran; Wu, Qiuwei; Rasmussen, Claus Nygaard; Guo, Qinglai; Sun, Hongbin
}

Published in:

Proceedings of 2014 ISGT Europe

Link to article, DOI:

10.1109/ISGTEurope.2014.7028925

Publication date:

2014

Document Version

Peer reviewed version

Link back to DTU Orbit

Citation (APA):

Zhao, H., Wu, Q., Rasmussen, C. N., Guo, Q., \& Sun, H. (2014). Distributed Model Predictive Control for Active Power Control of Wind Farm. In Proceedings of 2014 ISGT Europe (pp. 1-6). IEEE.

https://doi.org/10.1109/ISGTEurope.2014.7028925

\section{General rights}

Copyright and moral rights for the publications made accessible in the public portal are retained by the authors and/or other copyright owners and it is a condition of accessing publications that users recognise and abide by the legal requirements associated with these rights.

- Users may download and print one copy of any publication from the public portal for the purpose of private study or research.

- You may not further distribute the material or use it for any profit-making activity or commercial gain

- You may freely distribute the URL identifying the publication in the public portal

If you believe that this document breaches copyright please contact us providing details, and we will remove access to the work immediately and investigate your claim. 


\title{
Distributed Model Predictive Control for Active Power Control of Wind Farm
}

\author{
Haoran Zhao ${ }^{1}$, Qiuwei $\mathrm{Wu}^{1}$,Claus Nygaard Rasmussen ${ }^{1}$, Qinglai Guo ${ }^{2}$ and Hongbin Sun $^{2}$ \\ ${ }^{1}$ Department of Electrical Engineering, Technical University of Denmark \\ Kgs. Lyngby, 2800 Denmark \\ \{hzhao, qw, cnras\}@elektro.dtu.dk \\ ${ }^{2}$ Department of Electrical Engineering, Tsinghua University \\ Beijing 100084, China \\ \{guoqinglai, shb\}@tsinghua.edu.cn
}

\begin{abstract}
This paper presents the active power control of a wind farm using the Distributed Model Predictive Controller (DMPC) via dual decomposition. Different from the conventional centralized wind farm control, multiple objectives such as power reference tracking performance and wind turbine load can be considered to achieve a trade-off between them. Additionally, DMPC is based on communication among the subsystems. Through the interaction among the neighboring subsystems, the global optimization could be achieved, which significantly reduces the computation burden. It is suitable for the modern large-scale wind farm control.
\end{abstract}

Index Terms-Active power control, D-MPC, dual decomposition, multi-objective, wind farm control.

\section{NOMENCLATURE}

\section{A. Indexes and Sets}

$i \in N_{\mathrm{t}} \quad$ Wind turbine units.

$k \in N_{\mathrm{p}}$ Steps in prediction horizon of MPC.

$t \in T \quad$ Time steps in simulation.

$\mathbb{R}^{m \times n} \quad m \times n$ matrix whose elements are real numbers.

\section{B. Variables}

$P_{\text {ref }}^{\mathrm{WT}} \quad$ Reference power of wind turbine (MW).

$P_{\mathrm{g}} \quad$ Power generation of wind turbine (MW).

$T_{\mathrm{r}} \quad$ Rotor torque $(\mathrm{MNm})$.

$T_{\mathrm{s}} \quad$ Shaft torque (MNm).

$F_{\mathrm{t}} \quad$ Thrust force of the nacelle (MN).

$\beta \quad$ Pitch angle (deg).

$\omega_{\mathrm{r}}, \omega_{\mathrm{g}}, \omega_{\mathrm{f}}$

Rotor speed, generator speed and filtered generator speed $(\mathrm{rad} / \mathrm{s})$.

$\tau_{\omega} \quad$ Time constant of the generator speed filter.

$v_{\mathrm{s}} \quad$ Wind speed $(\mathrm{m} / \mathrm{s})$.

$\overline{v_{\mathrm{s}}} \quad$ Mean value of $v_{\mathrm{s}}$ over a certain period $(\mathrm{m} / \mathrm{s})$.

$\eta \quad$ Gear box ratio.

$\overline{P_{\mathrm{ref}}^{\mathrm{WT}}} \quad$ Power reference for the $i$ th D-MPC (MW).

$\frac{P_{\mathrm{g}}^{\mathrm{WT}}}{P_{i}}$ Power generation for the $i$ th D-MPC (MW).

$\frac{P_{\mathrm{g}}}{T_{\mathrm{S}}^{\mathrm{WT}}}$

$\frac{\mathrm{T}_{\mathrm{s}}}{F_{\mathrm{t}}^{\mathrm{WT}}}$

$P_{\text {ref }}^{F_{\text {WT }}}$

Torque reference for the $i$ th D-MPC (MNm).

Thrust force reference for the $i$ th D-MPC (MN). Power reference for the $i$ th wind turbine (MW). Total power reference of the wind farm (MW). $\alpha_{i} \quad$ Distribution factor of $P_{\mathrm{ref}}^{\mathrm{wfc}}$ for the $i$ th wind turbine.

C. Parameters

$\mu \quad$ Generator efficiency.

$K_{\mathrm{P}}, K_{\mathrm{I}}$ Proportional and integral gain of PI controller for pitch control.

$P_{\text {ref }}^{0}, \beta^{0}, \omega_{\mathrm{g}}^{0}, v_{\mathrm{s}}^{0}$

Power reference, pitch angle, generator speed and wind speed at the operating point.

$J \quad$ Equivalent inertia $\left(\mathrm{kg} \cdot \mathrm{m}^{2}\right)$.

$J_{\mathrm{r}}, J_{\mathrm{g}} \quad$ Rotor inertia and generator inertia $\left(\mathrm{kg} \cdot \mathrm{m}^{2}\right)$.

$K_{\beta T_{\mathrm{r}}}, K_{\omega_{\mathrm{r}} T_{\mathrm{r}}}, K_{v_{\mathrm{s}} T_{\mathrm{r}}}, K_{\beta F_{\mathrm{t}}}, K_{\omega_{\mathrm{r}} F_{\mathrm{t}}}, K_{v_{\mathrm{s}} F_{\mathrm{t}}}$ Coefficients derived from the Taylor approximation of $T_{\mathrm{r}}$ and $F_{\mathrm{t}}$ at the operating point.

$n_{\mathrm{t}} \quad$ Wind turbine number of the wind farm.

$n_{\mathrm{p}} \quad$ Prediction horizon of MPC.

$Q_{P}, Q_{T}, Q_{F}$

Weighting factors for the cost function in D-MPC.

$H_{i} \quad$ Hessian matrix for the standard Quadratic Programming (QP) of the $i$ th D-MPC.

$g_{i} \quad$ Coefficient vector for the standard Quadratic Programming (QP) of the $i$ th D-MPC.

$\lambda, \kappa, \xi \quad$ Dual variables for decomposition.

\section{INTRODUCTION}

Nowadays, wind energy has become the fastest developing renewable energy around the world. According to the scenarios of European Wind Energy Association (EWEA), wind energy should meet $15.7 \%$ of EU electricity demand of $230 \mathrm{GW}$ in 2020 , and by $2030,28.5 \%$ of $400 \mathrm{GW}$ [1]. With the growing wind power penetration level, wind turbines and wind farms are required to meet the more stringent technical requirements for contrallability by system operators [2]. At the wind turbine level, the dynamic response and controllability of modern Variable Speed Wind Turbines (VSWTs) are largely improved due to the development of power electronics [3], [4]. At the wind farm level, the requirements specify different types of power control: absolute power limitation, delta limitation, balance control, stop control, ramp limitation and fast down regulation to support system protection [5]. To fulfill these 
requirements, a wind farm should be capable of tracking the specific power references. In other words, the modern wind farm is required to operate much more like a conventional power plant and ultimately to replace conventional power plants.

The control scheme of a wind farm is implemented either by utilization of a separate energy storage device or through partial loading of wind turbines [6]. However, with the increasing scale of wind farms, the additional capital investment and maintenance cost of energy storage would be too high. The coordination of the wind turbines is a practical solution. In [6], the additional power reference is proposed to spread over all the turbines proportionally to their actual output power. In [5], the dispatch function of each turbine is based on the available power. The work above focuses only on the tracking performance of the reference power. The alleviation of wind turbine load, referring to the forces and moments experienced by the wind turbine structure, is neglected. That will significantly shorten the service lifetime of wind turbines [7].

The Model Predictive Control (MPC) scheme based on multi-objective performance optimization is an effective solution to handle this problem. It makes use of the receding horizon principle such that a finite-horizon optimal control problem is solved over a fixed interval of time [8]. A Centralized Model Predictive Control (C-MPC) strategy considering the trade-off between tracking performance and alleviation of wind turbine loads is proposed in [9]. However, the dimension of the matrices for optimization problem become very large with a large-scale wind farm and the computation burden is very heavy. The cooperative Distributed MPC (D-MPC) concept is developed to solve the same optimization problems as C-MPC with reduced computation load. Among the different distributed algorithms ([10], [11]), most of them are based on the property that the (sub)gradient to the dual of optimization problems can be handled in distributed fashion [12]. This approach is referred to as dual decomposition. The fast gradient method used in dual decomposition was originally proposed in early 1980s and has attracted more and more attention for D-MPC in the past few years [13], [14]. Compared with the standard gradient methods, the convergence rate can be largely improved. The parallel generalized fast dual gradient method proposed in [15] is adopted to design the wind farm D-MPC controller in this paper.

The paper is organized as follows: Section II describes the wind farm controller based on the D-MPC. In Section III, the linearization of wind turbine model for the wind farm controller is discussed. Section III explains the design of the D-MPC for a wind farm. Case studies with the developed DMPC are presented and discussed in Section IV. In the end, the conclusion is drawn.

\section{WIND FARM CONTROL BASED ON D-MPC}

The conventional wind farm control setup is illustrated in Fig. 1. Although both active and reactive power is labeled, only active power is considered in this paper. It is a two-level control system. At the wind farm control level, the wind farm controller behaves like a centralized unit. Different approaches described above (including C-MPC) could be applied to provide the required power at the Point of Common Coupling (PCC) by distributing the power references $P_{\text {ref }}^{\mathrm{WT}_{i}}$ to the wind turbines. Its inputs include the demand signal from the system operator, measurements at the PCC and available power from the wind turbines. At the local control level, the reference signals for converters and blade pitch controller of each wind turbine are generated according to $P_{\mathrm{ref}}^{\mathrm{WT}_{i}}$.

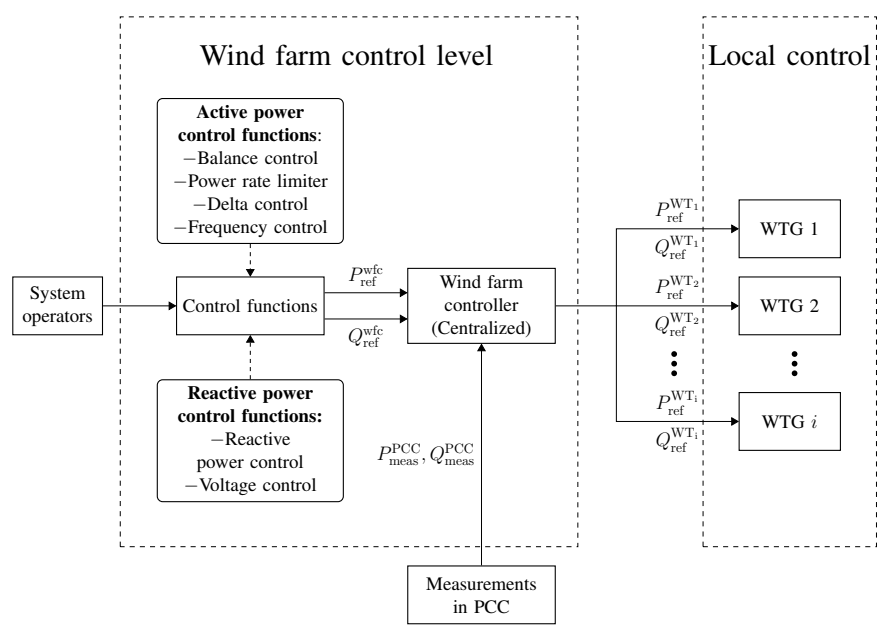

Fig. 1. Conventional control structure of wind farm

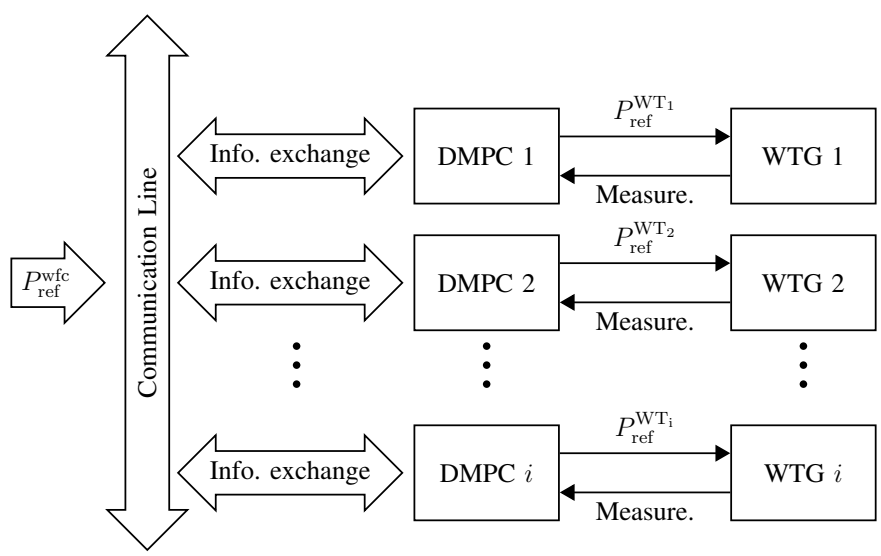

Fig. 2. D-MPC based control structure of wind farm

A D-MPC based control structure of wind farm is shown in Fig. 2. Each wind turbine is considered as a subsystem and regulated by its local D-MPC. A communication network allows the collaboration among the D-MPCs and ensures the improvement of global system performance. Obviously, the computation burden is significantly reduced compared with the centralized case.

\section{Wind TURBINE MODELING FOR D-MPC}

A wind turbine system is a nonlinear system including aerodynamics, drive train, tower, generator, pitch actuator and 
the wind turbine controller, as shown in Fig. 3. The main purpose of this section is to derive a simplified wind turbine prediction model for the D-MPC design of a wind farm. Since the sampling time of wind farm control is in seconds, the fast electromagnetic transients can be ignored. The torque control can be assumed to be perfect and generator efficiency $\mu$ is well compensated in WTG controller. Therefore, $P_{\mathrm{ref}}^{\mathrm{WT}}=P_{\mathrm{g}}$. Additionally, the low speed dynamics of shaft torque $T_{\mathrm{s}}$ and the thrust force of the nacelle $F_{\mathrm{t}}$ should be captured in order to represent the alleviation of wind turbine load.

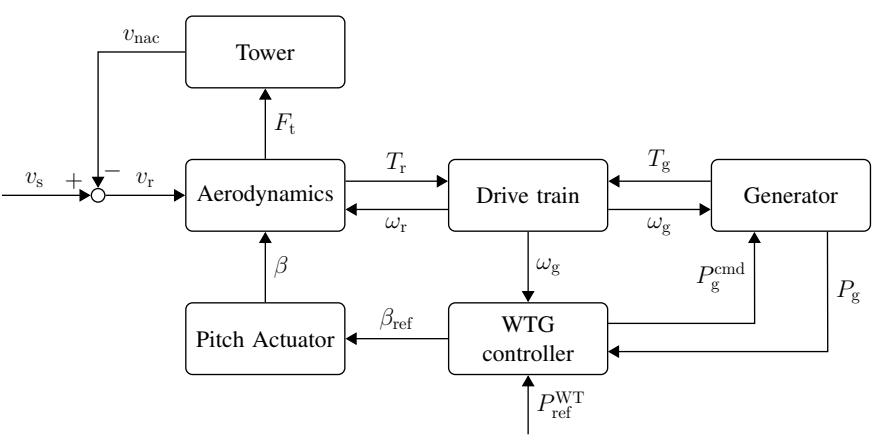

Fig. 3. Block diagram of the single wind turbine model [16]

A wind turbine model which fulfills the requirements above is introduced in [9]. Its state-space form around an operating point is expressed as follows:

$$
\begin{aligned}
& \dot{x}=A x+B u+E d \\
& z=C x+D u+F d
\end{aligned}
$$

where $x, u, d$ and $z$ indicate state, input, disturbance and output vectors: $x=\left[\beta, \omega_{\mathrm{r}}, \omega_{\mathrm{f}}\right]^{\prime}, u=P_{\mathrm{ref}}^{\mathrm{WT}}, d=v_{\mathrm{s}}, z=$ $\left[P_{\mathrm{g}}, F_{\mathrm{t}}, T_{\mathrm{s}}\right]^{\prime}$.

The state space matrices are:

$$
\begin{aligned}
& A=\left[\begin{array}{ccc}
0 & -\frac{K_{\mathrm{P}} \eta}{\tau_{\omega}} & \frac{K_{\mathrm{P}}-K_{\mathrm{I}} \tau_{\omega}}{\tau_{\omega}} \\
\frac{K_{\beta T_{\mathrm{r}}}}{J} & \frac{K_{\omega_{\mathrm{r}} T_{\mathrm{r}}}}{J}+\frac{1}{J} \frac{P_{\mathrm{ref}}^{0} \eta}{\mu \omega_{\mathrm{g}}^{02}} & 0 \\
0 & \frac{i}{\tau_{\omega}} & -\frac{1}{\tau_{\omega}}
\end{array}\right], \\
& B=\left[\begin{array}{c}
0 \\
-\frac{\eta}{J \mu \omega_{\mathrm{g}}^{0}} \\
0
\end{array}\right], E=\left[\begin{array}{c}
0 \\
\frac{K v_{\mathrm{s}} T_{\mathrm{r}}}{J} \\
0
\end{array}\right] \text {, } \\
& C=\left[\begin{array}{ccc}
0 & 0 & 0 \\
K_{\beta F_{\mathrm{t}}} & K_{\omega_{\mathrm{r}} F_{\mathrm{t}}} & 0 \\
\frac{\eta^{2} J_{\mathrm{g}} K_{\beta T_{\mathrm{r}}}}{J} & \frac{i^{2} J_{\mathrm{g}} K_{\omega_{\mathrm{r}} T_{\mathrm{r}}}}{J}-\frac{\eta^{2} J_{\mathrm{r}} P_{\mathrm{ref}}^{0}}{J \mu \omega_{\mathrm{g}}^{2}} & 0
\end{array}\right] \text {, } \\
& D=\left[\begin{array}{c}
1 \\
0 \\
\frac{1}{\mu \omega_{\mathrm{g}}^{0}}
\end{array}\right], F=\left[\begin{array}{c}
0 \\
K_{v_{\mathrm{s}} F_{\mathrm{t}}} \\
\frac{\eta^{2} J_{\mathrm{g}} K_{v_{\mathrm{s}} T_{\mathrm{r}}}}{J}
\end{array}\right] \text {. }
\end{aligned}
$$

The corresponding parameters and variables are defined in nomenclature. The equivalent inertia $J$ is calculated by $J=$ $J_{\mathrm{r}}+\eta^{2} J_{\mathrm{g}} . K_{\beta T_{\mathrm{r}}}, K_{\omega_{\mathrm{r}} T_{\mathrm{r}}}, K_{v_{\mathrm{s}} T_{\mathrm{r}}}, K_{\beta F_{\mathrm{t}}}, K_{\omega_{\mathrm{r}} F_{\mathrm{t}}}$ and $K_{v_{\mathrm{s}} F_{\mathrm{t}}}$ are the coefficients derived from the Taylor approximation of $T_{\mathrm{r}}$ and $F_{\mathrm{t}}$ at the operating point, given by:

$$
\begin{aligned}
& K_{\beta T_{\mathrm{r}}}=\left.\frac{\partial T_{\mathrm{r}}}{\partial \beta}\right|_{\beta^{0}, \eta \omega_{g}^{0}, v_{\mathrm{s}}^{0}}, K_{\omega_{\mathrm{r}} T_{\mathrm{r}}}=\left.\frac{\partial T_{\mathrm{r}}}{\partial \omega_{\mathrm{r}}}\right|_{\beta^{0}, \eta \omega_{g}^{0}, v_{\mathrm{s}}^{0}}, \\
& K_{v_{\mathrm{s}} T_{\mathrm{r}}}=\left.\frac{\partial T_{\mathrm{r}}}{\partial v_{\mathrm{s}}}\right|_{\beta^{0}, \eta \omega_{g}^{0}, v_{\mathrm{s}}^{0}}, K_{\beta F_{\mathrm{t}}}=\left.\frac{\partial F_{\mathrm{t}}}{\partial \beta}\right|_{\beta^{0}, \eta \omega_{g}^{0}, v_{\mathrm{s}}^{0}}, \\
& K_{\omega_{\mathrm{r}} F_{\mathrm{t}}}=\left.\frac{\partial F_{\mathrm{t}}}{\partial \omega_{\mathrm{r}}}\right|_{\beta^{0}, \eta \omega_{g}^{0}, v_{\mathrm{s}}^{0}}, K_{v_{\mathrm{s}} F_{\mathrm{t}}}=\left.\frac{\partial F_{\mathrm{t}}}{\partial v_{\mathrm{s}}}\right|_{\beta^{0}, \eta \omega_{g}^{0}, v_{\mathrm{s}}^{0}} .
\end{aligned}
$$

According to the discretization method introduced in [17], the wind turbine dynamic is described by the following linear, discrete, time-invariant system. The formulation of $A_{\mathrm{d}}, B_{\mathrm{d}}$, $C_{\mathrm{d}}, D_{\mathrm{d}}, E_{\mathrm{d}}$ and $F_{\mathrm{d}}$ depending on the sampling time is elaborated in [17].

$$
\begin{aligned}
x(k+1) & =A_{\mathrm{d}} x(k)+B_{\mathrm{d}} u(k)+E_{\mathrm{d}} d(k) \\
z_{i}(k) & =C_{\mathrm{d}} x(k)+D_{\mathrm{d}} u(k)+F_{\mathrm{d}} d(k)
\end{aligned}
$$

\section{Distributed Model Predictive Control via DUAL DECOMPOSITION WITH FAST GRADIENT METHOD}

\section{A. MPC Problem formulation}

The cost function of the D-MPC design takes both the tracking performance of the wind farm power reference and the alleviation of wind turbine load into account. The reference values should be firstly decided. During the wind farm operation, it is assumed that the mean wind speed $\overline{v_{\mathrm{s}}}$ of a certain period (10 minutes used in [9]) can be estimated and an initial distribution of individual wind turbine power references for this period is known. Therefore, the power reference for the $i$ th wind turbine $\overline{P_{\text {ref }}^{\mathrm{WT}_{i}}}$ can be calculated by

$$
\overline{P_{\mathrm{ref}}^{\mathrm{WT}}}=\alpha_{i} P_{\mathrm{ref}}^{\mathrm{wfc}}, \quad \text { with } \sum_{i=1}^{n_{\mathrm{t}}} \alpha_{i}=1 .
$$

Accordingly, other steady state variables, e.g. the shaft torque $\overline{T_{\mathrm{s}} \mathrm{WT}_{i}}$, can be determined. By defining:

$$
\begin{array}{r}
P_{\mathrm{g}}^{\mathrm{WT}_{i}}(k)=S_{1} \cdot z_{i}(k), S_{1}=[1,0,0], \\
T_{\mathrm{s}}^{\mathrm{WT}_{i}}(k)=S_{2} \cdot z_{i}(k), S_{2}=[0,1,0], \\
F_{\mathrm{t}}^{\mathrm{WT}_{i}}(k)=S_{3} \cdot z_{i}(k), S_{3}=[0,0,1], \\
u_{i}=\left[u_{i}(0), \ldots, u_{i}\left(n_{\mathrm{p}}-1\right)\right]^{\prime},\left(u_{i} \in \mathbb{R}^{n_{\mathrm{p}} \times 1}\right), \\
u=\left[u_{1}^{\prime}, \ldots, u_{n_{\mathrm{t}}}^{\prime}\right]^{\prime},\left(u_{i} \in \mathbb{R}^{\left(n_{\mathrm{p}} \cdot n_{\mathrm{t}}\right) \times 1}\right),
\end{array}
$$

the MPC problem can be formulated as follows:

$$
\begin{aligned}
\min _{u} \sum_{i=1}^{n_{\mathrm{t}}} & \left(\sum_{k=0}^{n_{\mathrm{p}}}\left\|S_{1} \cdot z_{i}(k)-\overline{P_{\mathrm{ref}}^{\mathrm{WT}}}\right\|_{Q_{P}}^{2}\right. \\
+ & \sum_{k=0}^{n_{\mathrm{p}}}\left\|S_{2} \cdot z_{i}(k)-\overline{T_{\mathrm{s}}^{\mathrm{WT}_{i}}}\right\|_{Q_{T}}^{2} \\
& \left.+\sum_{k=0}^{n_{\mathrm{p}}-1}\left\|\Delta\left(S_{3} \cdot z_{i}(k)\right)\right\|_{Q_{F}}^{2}\right)
\end{aligned}
$$


subject to

$$
\begin{array}{r}
x_{i}(k+1)=A_{\mathrm{d}} x_{i}(k)+B_{\mathrm{d}} u_{i}(k)+E_{\mathrm{d}} d_{i}(k) \\
\forall i, k=0, \ldots, n_{\mathrm{p}}-1 \\
z_{i}(k)=C_{\mathrm{d}} x_{i}(k)+D_{\mathrm{d}} u_{i}(k)+F_{\mathrm{d}} d_{i}(k) \\
\forall i, k=0, \ldots, n_{\mathrm{p}} \\
x_{i}(0)=x_{i}(t) \\
\sum_{i=1}^{n_{\mathrm{t}}} u_{i}(0)=P_{\mathrm{ref}}^{\mathrm{wfc}} \\
x_{i} \in \mathcal{X}_{i}, \\
u_{i} \in \mathcal{U}_{i},
\end{array}
$$

The second and third terms in the cost function (4) are used to penalize the deviation of the shaft torque from the steady state and the derivative of the thrust force in order to reduce the wind turbine load. $\mathcal{X}_{i}$ and $\mathcal{U}_{i}$ represent the local state and control input constraints, respectively. As the optimization variable $u$, the first values $\left(u_{i}(0), i \in\left[1, \ldots, n_{\mathrm{t}}\right]\right)$ are taken as the control inputs for each turbine. The control inputs are coupled whose summary equals to the power reference of the wind farm $P_{\text {ref }}^{\mathrm{wfc}}$ (see (8)).

\section{B. D-MPC algorithm via dual decomposition}

As introduced in [17], the MPC problem (4) could be reformulated as a summary of standard Quadratic Programming (QP) problems with Hessian matrix $H_{i} \in \mathbb{R}^{n_{\mathrm{p}} \times n_{\mathrm{p}}}$ and coefficient vector $g_{i} \in \mathbb{R}^{n_{\mathrm{p}} \times 1}$ :

$$
\min _{u} \Phi=\sum_{i=1}^{n_{\mathrm{t}}} \Phi_{i}\left(u_{i}\right)=\sum_{i=1}^{n_{\mathrm{t}}}\left(\frac{1}{2} u_{i}^{\prime} H_{i} u_{i}+g_{i}^{\prime} u_{i}\right)
$$

subject to

$$
\begin{gathered}
G u=b \\
u \in \mathcal{U} .
\end{gathered}
$$

$H_{i}$ and $g_{i}$ can be calculated according to the discrete model of the $i$ th wind turbine and prediction horizon $n_{\mathrm{p}}$. More details are explained in [17]. The coupling of the control inputs can be equivalently rewritten as the equality constraint (12), where

$$
\begin{array}{r}
G=\left[G_{1}, \cdots, G_{n_{\mathrm{t}}}\right], G \in \mathbb{R}^{1 \times\left(n_{\mathrm{p}} \cdot n_{\mathrm{t}}\right)}, \\
G_{1}=G_{2}=\cdots G_{n_{\mathrm{t}}}=[1,0, \cdots, 0], G_{i} \in \mathbb{R}^{1 \times n_{\mathrm{p}}}, \\
b=P_{\mathrm{ref}}^{\mathrm{wfc}} .
\end{array}
$$

By introducing dual variable vectors $\lambda \in \mathbb{R}^{1}, \kappa \in \mathbb{R}^{1}$ and $\xi \in \mathbb{R}^{1}$, the coupled equality constraint (12) can be decomposed. The parallel fast gradient method via dual decomposition proposed in [15] is adopted in this paper, which has a guaranteed convergence and improvement of the convergence rate from $\mathcal{O}(1 / m)$ to $\mathcal{O}\left(1 / m^{2}\right)$ ( $m$ indicates the iteration number). The proofs regarding the guarantee of convergence and convergence are described in [14]. Due to the limitation of space, only the implementation procedure for the wind farm control is stated below. Normally, the iteration process stops if the stopping criterion is met. In this study, fixed number of iteration $m_{\max }$ is selected as the stopping criterion in order to limit the online computation time.

\section{Parallel fast dual gradient method}

Require: Initial guesses $\kappa^{[1]}=\lambda^{[0]}, \xi^{[1]}=1$.

for: $m=1, \ldots, m_{\max }$, do

1) Form and send $\kappa^{[m]}$ to all wind turbines.

2) Update $u^{[m]}$ by solving the local optimization with augmented cost function:

$$
u_{i}^{[m]}=\arg \min _{u_{i}}\left\{\Phi_{i}+u_{i}^{\prime} G_{i}^{\prime} \kappa^{[m]}\right\}
$$

3) Receive $u_{i}^{[m]}$ from each turbine and form $u^{[m]}=$ $\left[u_{1}^{[m]^{\prime}}, \cdots, u_{n_{\mathrm{t}}}^{[m]^{\prime}}\right]^{\prime}$.

4) Update the dual variables:

$$
\begin{aligned}
& \lambda^{[m]}=\kappa^{[m]}+\mathbf{L}^{-1}\left(G u^{[m]}-b\right) \\
& \xi^{[m+1]}=\frac{1+\sqrt{1+4\left(\xi^{[m]}\right)^{2}}}{2} \\
& \kappa^{[m+1]}=\lambda^{[m]}+\left(\frac{\xi^{[m]}-1}{\xi^{[m+1]}}\right)\left(\lambda^{[m]}-\lambda^{[m-1]}\right)
\end{aligned}
$$

end for

The Hessian matrix $H$ is block diagonal: $H$ := $\operatorname{blkdiag}\left(H_{1}, \ldots, H_{n_{\mathrm{t}}}\right)$. According to [15], the matrix $\mathbf{L}$ in the algorithm should satisfy $\mathbf{L} \succeq G H^{-1} G^{\prime}$. In this paper, $\mathbf{L}=G H^{-1} G^{\prime}$ is chosen.

\section{CASE STUdy}

In this section, the simulation results of a centralized wind farm controller are used to compare with these with the D-MPC. A wind farm with $10 \times 5 \mathrm{MW}$ wind turbines is adopted as the test system. The sampling time $t_{\mathrm{s}}$ is set $1 \mathrm{~s}$. During the simulation, the mean wind speed for each wind turbine is assumed to be known and over the rated wind speed $(11.5 \mathrm{~m} / \mathrm{s})$. Hence, all the wind turbines operate in the partial loading mode. The wind field modeling for the wind farm is created in SimWindFarm [18], which is a toolbox for dynamic wind farm model, simulation and control. The wake effects of the wind turbines are also considered. The power reference of the wind farm $P_{\text {ref }}^{\text {wfc }}$ is defined $40 \mathrm{MW}$ and kept constant. Timing and communication delay is negligible in the simulation. The simulation time is $300 \mathrm{~s}$.

For the centralized wind farm controller, the initial power reference for all the wind turbines are defined the same: $P_{\text {ref }}^{\mathrm{WF}_{i}}=\frac{P_{\mathrm{ref}}^{\mathrm{wrfc}}}{n_{\mathrm{t}}}=4 \mathrm{MW}$ according to the proportional distribution algorithm.

For the D-MPC, the wind speed is considered as the measurable disturbance and the values for the prediction horizon are based on persistence assumption, which is suitable for the short-term prediction. Therefore, the prediction horizon $n_{\mathrm{p}}=10$. To compare the control effects of different weighting factors on the wind turbine load reduction, two scenarios are defined in Table I. 
TABLE I

SCENARIO DEFINITION

\begin{tabular}{l|c|c|c}
\hline & $Q_{P}$ & $Q_{T}$ & $Q_{F}$ \\
\hline Scenario 1 & 1 & 5 & 2 \\
\hline Scenario 2 & 1 & 10 & 2 \\
\hline
\end{tabular}

(a)

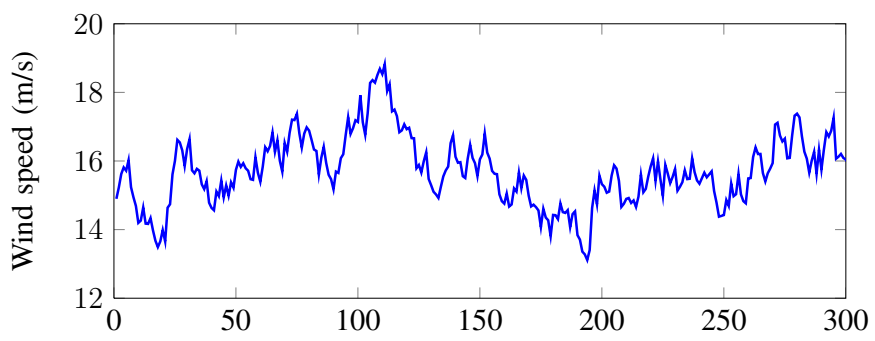

(b)

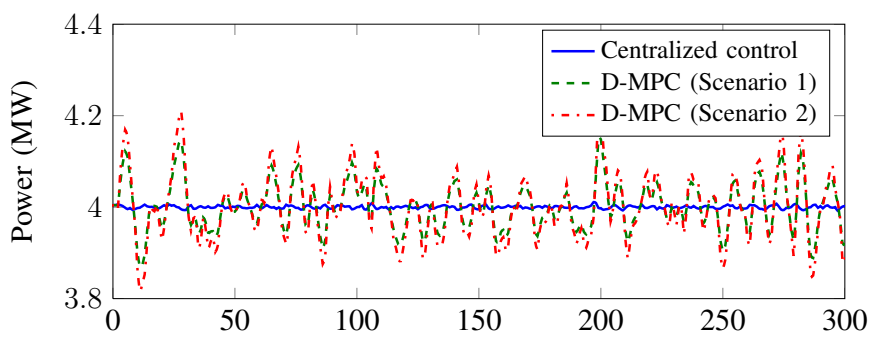

(c)

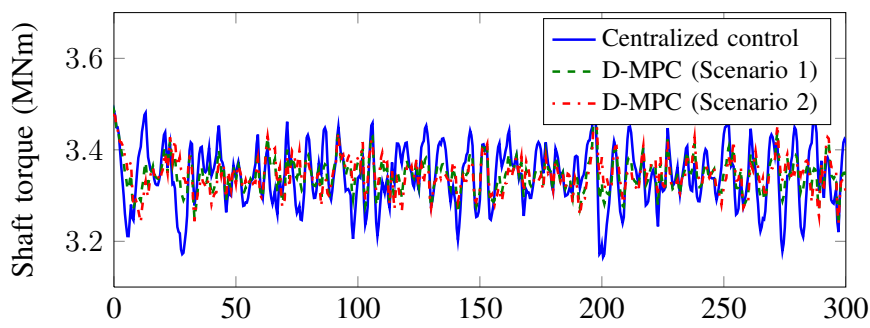

(d)

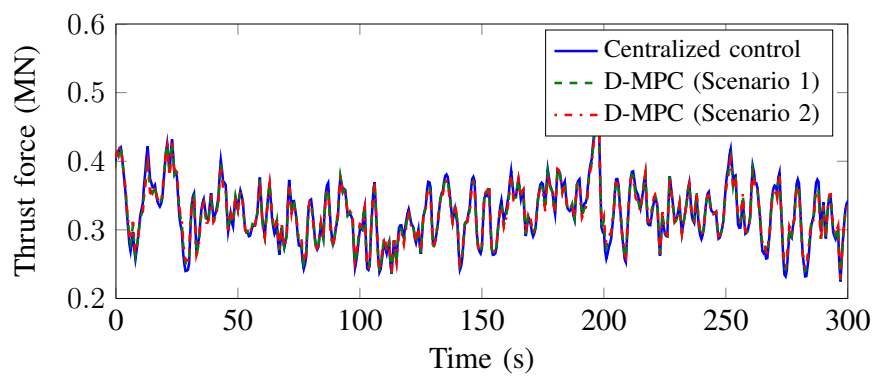

Fig. 4. Simulation results of WT 01

The comparison for a single wind turbine (WT 01) with the two controllers is taken as an example and illustrated in Fig. 4. It can be observed that the power output by D-MPC varies following the wind speed (see Fig. 4(a)). Accordingly, the deviation of the shaft torque $T_{\mathrm{s}}$ is significantly reduced by D-MPC (see Fig. 4(b)). With larger weighting factor of $T_{\mathrm{s}}$ (Scenario 2), the reduction becomes more than that of Scenario 1. Due to the small weighting factor, the thrust force change is not obvious (see Fig. 4(c)).
Regarding the whole wind farm, the simulation statistics are listed in Table II-IV, where $\sigma\left(P_{\mathrm{gen}}^{\mathrm{wfc}}\right)$ indicates the standard deviation of the output power, $\sigma T_{\mathrm{s}}$ and $\sigma \Delta F_{\mathrm{t}}$ represent the shaft and thrust-induced loads, respectively.

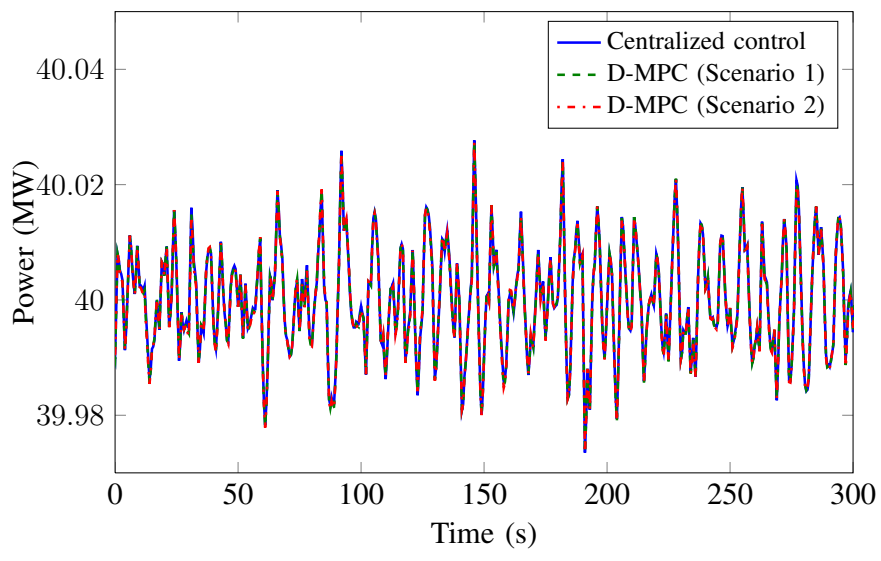

Fig. 5. Active power of the wind farm $P_{\text {gen }}^{\text {wfc }}$

TABLE II

Simulation Statistics $\sigma\left(P_{\mathrm{gen}}^{\mathrm{wfc}}\right)$ in MW

\begin{tabular}{c|c|c|c}
\hline & $\begin{array}{c}\text { Centralized } \\
\text { Control }\end{array}$ & $\begin{array}{c}\text { D-MPC } \\
\text { Scenario 1 }\end{array}$ & $\begin{array}{c}\text { D-MPC } \\
\text { Scenario 2 }\end{array}$ \\
\hline Wind Farm & 0.0091 & $0.0091(0.00 \%)$ & $0.0091(0.00 \%)$ \\
\hline
\end{tabular}

The comparison of output power $P_{\text {gen }}^{\text {wfc }}$ for both controllers is shown in Fig. 5. The waveforms are observed around the reference value $\left(P_{\mathrm{gen}}^{\mathrm{wfc}}=40 \mathrm{MW}\right)$ and almost identical. This observation is proved by the calculated standard deviations $\sigma\left(P_{\mathrm{gen}}^{\mathrm{wfc}}\right)$ for both controller, which are the same. The value is $0.0091 \mathrm{MW}$, only $0.022 \%$ of the power reference $(40 \mathrm{MW})$ which is within the tolerance range.

According to the statistics in Table III, the shaft torque deviation is alleviated significantly with D-MPC for each wind turbine, compared with the centralized control. For Scenario 1 , the reduction percentages of standard deviation are between $37.61 \%$ and $47.01 \%$. By increasing the weight $Q_{T}$ in Scenario 2 , the reductions become larger which are between $39.42 \%$ and $49.49 \%$.

The thrust force change is also alleviated in each wind turbine with D-MPC. For Scenario 1, the reduction percentages of standard deviation are between $2.85 \%$ and $5.35 \%$. For Scenario 2, the thrust force is affected by increasing $Q_{T}$, the reductions become a little larger which are between $3.45 \%$ and $6.10 \%$.

\section{CONCLUSION}

In this paper, the D-MPC via dual decomposition with fast gradient method is used for the active power control of a wind farm. Compared with the centralized control, shaft torque and thrust force of wind turbines are included in the cost function to achieve the balance between the power 
TABLE III

Simulation Statistics $\sigma\left(T_{\mathrm{S}}\right)$ in MNm

\begin{tabular}{c|c|c|c}
\hline & $\begin{array}{c}\text { Centralized } \\
\text { Control }\end{array}$ & $\begin{array}{c}\text { D-MPC } \\
\text { Scenario 1 }\end{array}$ & $\begin{array}{c}\text { D-MPC } \\
\text { Scenario 2 }\end{array}$ \\
\hline WT 01 & 0.0612 & $0.0354(-42.08 \%)$ & $0.0346(-43.47 \%)$ \\
\hline WT 02 & 0.0643 & $0.0358(-44.36 \%)$ & $0.0339(-47.22 \%)$ \\
\hline WT 03 & 0.0698 & $0.0370(-47.01 \%)$ & $0.0352(-49.49 \%)$ \\
\hline WT 04 & 0.0651 & $0.0385(-40.87 \%)$ & $0.0375(-42.36 \%)$ \\
\hline WT 05 & 0.0554 & $0.0333(-39.87 \%)$ & $0.0333(-39.87 \%)$ \\
\hline WT 06 & 0.0645 & $0.0348(-45.99 \%)$ & $0.0334(-48.15 \%)$ \\
\hline WT 07 & 0.0715 & $0.0414(-42.13 \%)$ & $0.0394(-44.93 \%)$ \\
\hline WT 08 & 0.0688 & $0.0372(-45.98 \%)$ & $0.0355(-48.43 \%)$ \\
\hline WT 09 & 0.0674 & $0.0368(-45.34 \%)$ & $0.0362(-46.21 \%)$ \\
\hline WT 10 & 0.0802 & $0.0500(-37.61 \%)$ & $0.0486(-39.42 \%)$ \\
\hline
\end{tabular}

TABLE IV

Simulation Statistics $\sigma\left(\Delta F_{\mathrm{t}}\right)$ in MN

\begin{tabular}{c|c|c|c}
\hline & $\begin{array}{c}\text { Centralized } \\
\text { Control }\end{array}$ & $\begin{array}{c}\text { D-MPC } \\
\text { Scenario 1 }\end{array}$ & $\begin{array}{c}\text { D-MPC } \\
\text { Scenario 2 }\end{array}$ \\
\hline WT 01 & 0.0192 & $0.0187(-2.91 \%)$ & $0.1798(-3.51 \%)$ \\
\hline WT 02 & 0.0180 & $0.0171(-4.24 \%)$ & $0.1791(-5.14 \%)$ \\
\hline WT 03 & 0.0184 & $0.0173(-4.93 \%)$ & $0.1739(-5.99 \%)$ \\
\hline WT 04 & 0.0180 & $0.0170(-4.95 \%)$ & $0.1812(-6.02 \%)$ \\
\hline WT 05 & 0.0172 & $0.0166(-2.85 \%)$ & $0.1800(-3.45 \%)$ \\
\hline WT 06 & 0.0180 & $0.0169(-4.67 \%)$ & $0.1787(-5.69 \%)$ \\
\hline WT 07 & 0.0188 & $0.0176(-5.35 \%)$ & $0.1811(-6.48 \%)$ \\
\hline WT 08 & 0.0196 & $0.0186(-4.06 \%)$ & $0.1758(-4.93 \%)$ \\
\hline WT 09 & 0.0172 & $0.0163(-4.60 \%)$ & $0.1849(-5.60 \%)$ \\
\hline WT 10 & 0.0215 & $0.0201(-5.03 \%)$ & $0.1846(-6.10 \%)$ \\
\hline
\end{tabular}

reference tracking and the alleviation of the wind turbine loads. Compared with the C-MPC, there is no need to solve largescale optimization problem. Therefore, the computation burden can be significantly reduced and it is potential for online MPC application in the modern large-scale wind farm.

\section{ACKNOWLEDGMENT}

The authors would thank Sino-Danish Center for Education and Research (SDC) for the financial support to the PhD project of "Coordinated control of wind power plants and energy storage systems".

\section{REFERENCES}

[1] A. Zervos, C. Kjaer, S. Azau. et al., "Pure Power wind energy targets for 2020 and 2030," European Wind Energy Association, Tech. Rep., 2011.

[2] I. Erlich and U. Bachmann, "Grid code requirements concerning connection and operation of wind turbines in germany," in Power Engineering Society General Meeting, 2005. IEEE. IEEE, 2005, pp. 1253-1257.

[3] A. D. Hansen and G. Michalke, "Multi-pole permanent magnet synchronous generator wind turbines' grid support capability in uninterrupted operation during grid faults," Renewable Power Generation, IET, vol. 3, no. 3, pp. 333-348, 2009.
[4] Z. Chen, J. M. Guerrero, and F. Blaabjerg, "A review of the state of the art of power electronics for wind turbines," IEEE Trans. Power Electronics, vol. 24, no. 8, pp. 1859-1875, 2009.

[5] P. E. Sørensen, A. D. Hansen, F. Iov, F. Blaabjerg, and M. H. Donovan, "Wind farm models and control strategies," Ris ̃̃ž National Library, Tech. Rep., 2005.

[6] Z. Lubosny and J. W. Bialek, "Supervisory control of a wind farm," IEEE Trans. Power Systems, vol. 22, no. 3, pp. 985-994, 2007.

[7] I. Munteanu, Optimal control of wind energy systems: towards a global approach, Springer, 2008.

[8] S. Teleke, M. E. Baran, S. Bhattacharya, and A. Q. Huang, "Optimal control of battery energy storage for wind farm dispatching," IEEE Trans. Energy Conversion, vol. 25, no. 3, pp. 787-794, 2010.

[9] V. Spudić, M. Jelavić, and M. Baotić, "Wind turbine power references in coordinated control of wind farms," Automatika-Journal for Control, Measurement, Electronics, Computing and Communications, vol. 52, no. 2, 2011.

[10] B. T. Stewart, A. N. Venkat, J. B. Rawlings, S. J. Wright, and G. Pannocchia, "Cooperative distributed model predictive control," Systems \& Control Letters, vol. 59, no. 8, pp. 460-469, 2010.

[11] M. D. Doan, T. Keviczky, and B. De Schutter, "An improved distributed version of han's method for distributed mpc of canal systems," in Symposium on Large Scale Systems: Theory and Applications, 2010.

[12] H. Everett III, "Generalized lagrange multiplier method for solving problems of optimum allocation of resources," Operations research, vol. 11, no. 3, pp. 399417, 1963.

[13] M. D. Doan, T. Keviczky, and B. De Schutter, "An iterative scheme for distributed model predictive control using fenchel's duality," Journal of Process Control, vol. 21, no. 5, pp. 746-755, 2011.

[14] P. Giselsson, M. D. Doan, T. Keviczky, B. D. Schutter, and A. Rantzer, "Accelerated gradient methods and dual decomposition in distributed model predictive control," Automatica, vol. 49, no. 3, pp. 829-833, 2013.

[15] P. Giselsson, "Improving fast dual ascent for MPC-Part I: The distributed case," arXiv preprint arXiv:1312.3012, 2013.

[16] M. Soltani, T. Knudsen, and T. Bak, "Modeling and simulation of offshore wind farms for farm level control," in European Offshore Wind Conference and Exhibition (EOW), 2009.

[17] J. M. Maciejowski, Predictive control: with constraints. Pearson education, 2002.

[18] J. D. Grunnet, M. Soltani, T. Knudsen, M. Kragelund, and T. Bak, "Aeolus toolbox for dynamic wind farm model, simulation and control," in Proc. of the 2010 European Wind Energy Conference, 2010. 